\title{
Liquidity provision and optimal bank regulation
}

\author{
Oz Shy* and Rune Stenbacka ${ }^{\dagger}$
}

\begin{abstract}
We extend the set of regulatory instruments for banks' liquidity provision by adding a policy instrument for controlling the fraction of perfectly-liquid accounts. We demonstrate how this instrument induces self-selection on behalf of depositors who are differentiated according to their probability of facing a liquidity shock. This selfselection leads to a market segmentation, which can break the bundling of deposits with liquidity risk and, thereby, enhance welfare. The optimal regulatory policy is explicitly characterized as a function of banks' investment return, and of depositors' gain from early withdrawals to fund a realized investment opportunity.
\end{abstract}

Key words banking regulation, liquidity, reserve requirement, narrow banking

JEL classification G21, G28

Accepted 18 May 2007

\section{Introduction}

In recent years, we have witnessed a rapid worldwide consolidation process of the banking industry. The securitization of markets has broken the traditional link between taking deposits and making loans. Nowadays, large corporations have direct access to international capital markets at terms, which might often outperform those of intermediated bank funding. Therefore, banks have to operate in a world with intensified competition in the markets for financial services: banking, brokerage as well as insurance. This development has serious consequences from the point of view of traditional banking, because, as Kay (1998) states, "The rational for the traditional association of functions that we call a bank has simply disappeared, and most of these specific functions - retail marketing of financial services, financial advice to companies, monitoring the creditworthiness of large companies - are better done by some specialist institution that is not necessarily a bank". Also, with the vast development of money market funds, insurance investment and investment via brokerage firms, and with the fast globalization of investment opportunities, consumers do not suffer a lack of investment opportunities and startup firms can raise capital in a wide variety of markets without approaching banks. In fact, given the large number of money

*WZB - Social Science Research Center, Berlin, Germany, and University of Haifa, Haifa, Israel. Email: ozshy@ozshy.com. From mid-July: Department of Economics, University of Michigan, Ann Arbor, USA.

${ }^{\dagger}$ Swedish School of Economics, Helsinki, Finland, and Department of Economics, Göteborg University, Göteborg, Sweden.

We thank two anonymous referees and an Editor of the Journal for most valuable comments on an earlier draft. Shy thanks the Aharon Meir Center for Banking at Bar-Ilan University for financial support. Stenbacka thanks RUESG (University of Helsinki) and The Yrjö Jahnsson Foundation for financial support. 
market funds and financial instruments existing today, consumers can always pick a ratio of risk and return that exactly matches their degree of risk aversion.

Faced with intense competition, from other types of financial markets or from rivals, banks make use of their retail deposit base as collateral for risky investment activities in securities markets, such as trading, market making and placing, as well as for traditional lending to illiquid long-term investment projects. In this way, the banks effectively bundle their deposit base with their risky investment activities. This bundling of deposits with risk generates a market failure, which is supported, and not corrected, by the regulatory environment where the banks' risks are effectively underwritten by the governments, and ultimately by the taxpayers. This applies in particular to banks that are large enough to enjoy full protection under the prevailing "too-big-to-fail" doctrine (see e.g. Feldman and Rolnick 1998).

Basically, the banks' bundling of deposits with illiquid and often risky investment activities generates a welfare distortion, because those depositors who wish to use bank services associated with deposit accounts might be willing to pay an extra fee to the bank in return for maintaining perfectly liquid and risk-free accounts. This market failure cannot be corrected within a regulatory framework with reserve requirements as the only instrument for restricting the banks' risk exposure.

In this article, we extend the set of instruments for the regulation of banks by adding the fraction of perfectly liquid accounts as a new regulatory instrument. By adding this instrument within the framework of a model with depositors differentiated according to their probability of facing a liquidity shock, the market failure generated by the bundling of deposits with liquidity risk can be reduced or eliminated. Based on depositor-specific private information each depositor can decide which type of account to use. Therefore, selfselection on behalf of the depositors induces a market segmentation, which can break the bundling of deposits with liquidity risk. We will delineate those circumstances under which the addition of perfectly liquid deposit accounts could represent a Pareto improvement relative to a banking industry where illiquid accounts represent the only channel whereby consumers can enjoy the deposit services offered by the banking industry. Furthermore, we characterize the optimal regulatory policy when the set of policy instruments includes the fraction of perfectly liquid accounts in addition to the traditional reserve requirements applied on illiquid and risky accounts. We also outline under which conditions the currently applied policy of applying only reserve requirements is optimal.

We conduct the analysis of optimal regulation using an oligopolistic industry structure with a variable degree of competition (as opposed to pure monopoly), because most banking industries are characterized to some degree by imperfect competition. Using this approach we are able to investigate whether and how intensified competition between banks affects the two regulatory instruments analyzed in the present paper. A low degree of competition reflects a near-monopoly industry. The major finding in this respect is that the introduction of the proposed regulatory variable for restricting the proportion of illiquid accounts promotes welfare for all degrees of competition in the banking industry, as reflected by the degree of bank differentiation in the context of our model.

The existing published literature views depository institutions as "pools of liquidity" providing households with insurance against idiosyncratic shocks to their consumption 
needs. In the influential model by Diamond and Dybvig (1983) banks provide liquidity to depositors, who are, ex ante, uncertain about their intertemporal preferences over consumption sequences (see also Bryant 1980; Villamill 1991). In that model, demand deposits are needed because liquidity shocks are not publicly observed and, therefore, cannot be insured. Diamond and Dybvig demonstrate how deposit contracts offer insurance to households and how such contracts can potentially induce a Pareto efficient allocation of risk. Diamond and Rajan (2001) have designed a model in which they defend the bundling of banks' deposits with illiquid and risky investment activities. That argument builds on the view that banks have specific collection skills with respect to the illiquid projects in their outstanding loan portfolio.

As Diamond and Dybvig (1983) originally pointed out, deposit insurance systems can eliminate inefficient Nash equilibria generated by pessimistic depositor expectations. Despite the indisputable insurance benefits, empirical observations as well as theoretical research convincingly demonstrate how federal deposit insurance will encourage banks to engage in excessive risk taking (see e.g. Cooper and Ross 1998). For that reason, researchers have systematically investigated mechanisms other than deposit insurance as instruments for reducing the instability of the banking system. In line with Freixas and Rochet (1997), the adoption of narrow banking seems to be the most natural mechanism to eliminate this instability. ${ }^{1}$

The research contributions evaluating the consequences of narrow banking have typically conducted comparisons between the polar cases of complete narrow banking and risky banking regulated by reserve requirements. ${ }^{2}$ In the present analysis, we contribute to this fundamental debate by introducing the possibility of designing banking systems where one fraction of the banking activities is required to obey the principles of narrow banking, whereas the complementary fraction operates as risky banking controlled by the socially-optimal reserve requirement. We essentially ask the following two questions. First, what is the optimal mixture of narrow banking and illiquid banking supported by reserve requirements? Second, what is the effect of intensified banking market competition on the optimal policy combination?

Our study is organized as follows. Section 2 presents the model. In Section 3 we calculate the equilibrium interest rates and fees. Section 4 characterizes the optimal regulatory policy for supporting a socially optimal system of liquidity provision by banks. In Section 4 we explore the consequences of deposit insurance systems for optimal regulation. Finally, Section 5 offers some concluding comments.

\section{The model}

Consider an imperfectly-competitive banking industry with two banks labeled as bank $A$ and $B$. Banks can offer two types of deposit accounts.

\footnotetext{
${ }^{1}$ Narrow banking refers to regulatory systems where the banks are required to back demand deposits entirely by safe and liquid short-term assets.

2 See, for example, Friedman (1960) or Wallace (1996).
} 
Accounts with partial liquidity ( $P$-type accounts): Banks must keep a fraction $\rho$ of all deposits completely liquid. The banks can allocate the remaining fraction $1-\rho$ for lending activities whereby banks finance borrowers' investment projects with limited liquidity.

Accounts with perfect liquidity (L-type accounts): Banks keep these deposit accounts completely liquid and ready for withdrawals at all times.

The P-type accounts closely resemble today's conventional bank accounts whereby banks are mandated to keep a regulated fraction of the deposits liquid, whereas the remaining fraction can be invested in a profit-maximizing way. The $L$-type accounts would capture, for example, accounts where the commercial bank is required to deposit the acquired resources with the central bank.

There are three periods. In period 1, banks determine their fees and interest rates. Based on these fees and interest rates, depositors determine which bank to make a deposit with, and whether to open a liquid account ( $L$-type account in what follows), or a partiallyliquid account ( $P$-type account in what follows). $P$-type accounts are subjected to a reserve requirement $\rho$. In period 2 , some depositors realize a liquidity need forcing them to attempt to withdraw their entire deposit. In period 3, banks collect the return on their own investments, liquidate all accounts, and pay interest on interest-bearing accounts.

\subsection{The regulator}

The regulator of the banking industry imposes two restrictions on banks. The first, denoted by $\rho(0 \leq \rho \leq 1)$, is the commonly practiced reserve requirement. That is, $\rho$ is the fraction of $P$-type deposits that the bank must keep liquid, whereas $(1-\rho)$ is the fraction of $P$-type deposits that banks use for lending activities for funding of credit worthy projects, which are illiquid in the short run.

The second policy instrument, denoted by $\delta(0 \leq \delta \leq 1)$, is the maximal fraction of accounts on which banks can maintain the minimal reserve requirement ( $P$-type accounts). Therefore, $(1-\delta)$ is the fraction of $L$-type accounts that must be kept 100 percent liquid. Accordingly, we will make use of the following terminology.

Definition 1 We say that the regulator allows/mandates

- Banking with partial liquidity if $\delta=1$

- Narrow banking if $\delta=0$

- $\quad$ Mixed banking if $0<\delta<1$.

Partially-liquid accounts, subjected to a minimum reserve requirement $\rho<1$, constitute what is widely observed in today's private banking. The fraction $\delta$ is not a policy instrument within the framework of current banking regulation. The academic literature on banking regulation has to a large extent focused on comparisons of narrow banking systems with banking systems operating with a minimal reserve requirement as the only policy instrument. In this respect, our analysis represents a more ambitious research task insofar as our goal is to characterize the socially optimal combination of the policy instruments $\rho$ and $\delta$ as the basis for the design of banking regulation. In particular, we will specify 
circumstances under which mixed banking is superior to banking with partial liquidity from a social point of view for all possible levels of mandated minimum reserve requirements.

A regulatory environment with $\delta$ as an added instrument induces a self-selection effect on behalf of depositors. The purpose of the present paper is to demonstrate how a policy combination $(\rho, \delta)$ differs from a policy where all accounts are only partially liquid and the regulator imposes a traditional reserve requirement at the level $(1-\delta)+\rho \delta$ on all deposit accounts.

\subsection{Depositors}

There is a continuum of uniformly distributed depositors indexed by the pair $(\lambda, x)$ on the unit square $[0,1] \times[0,1]$. This captures depositors who are differentiated along two dimensions. The banks are horizontally differentiated on the unit interval where bank $A$ is located at $x=0$, whereas bank $B$ is located at $x=1$. Each depositor allocates $\$ 1$ either to bank $A$ or bank $B$. The characteristic of horizontal differentiation, $x$, measures the disutility (transportation cost) associated with making a deposit with bank $A$, whereas $(1-x)$ measures the disutility associated with banking at $B$. Depositors are also heterogeneous with respect to $\lambda$, which measures depositors' probability of realizing a liquidity need in period 2. The idiosyncratic depositor characteristics $(x, \lambda)$ are private information of depositors and cannot be observed by the banks. Therefore, banks cannot make their fees and interest rates contingent on $\lambda$ or $x$.

Let $\beta$ denote a depositor's basic utility derived from the services obtained by opening a bank account and making the $\$ 1$ deposit. The variables $i_{A}$ and $i_{B}$ denote the deposit interest rates paid only on $P$-type accounts, whereas $f_{A}$ and $f_{B}$ denote the fees applied only on $L$-type accounts, for banks $A$ and $B$, respectively. Let $\theta_{A}$ and $\theta_{B}$, where $0 \leq \theta_{j} \leq 1$, denote the per-depositor amount of money available for withdrawal in period 2 from $P$-type accounts upon realizing a liquidity need. The parameters $\theta_{A}$ and $\theta_{B}$ are endogenously determined within our model. Finally, let $v$ denote the value of the opportunity faced by a depositor realizing a liquidity need in period $2 .^{3}$ That is, a higher value of $v$ makes an earlier withdrawal more beneficial to depositors. Altogether, the expected utility of a depositor indexed by $(\lambda, x)$ is given by

$$
U_{\lambda, x} \stackrel{\text { def }}{=} \begin{cases}\beta-\tau x+\lambda \theta_{A} v+i_{A} & \text { Deposits in a } P \text {-type account with bank } A \\ \beta-\tau x+\lambda v-f_{A} & \text { Deposits in an } L \text {-type account with bank } A \\ \beta-\tau(1-x)+\lambda \theta_{B} v+i_{B} & \text { Deposits in a } P \text {-type account with bank } B \\ \beta-\tau(1-x)+\lambda v-f_{B} & \text { Deposits in an } L \text {-type account with bank } B .\end{cases}
$$

Therefore, if all banks maintain 100 percent reserves on all accounts then $\theta_{A}=\theta_{B}=1$. In this case, depositors who realize a liquidity need (probability $\lambda$ ) can fully reach the full

\footnotetext{
${ }^{3}$ This could capture the deposit-specific opportunity of buying an urgent durable consumption good, of making an investment at favorable terms or of exploiting a good business opportunity. Models characterizing optimal bank regulation frequently do not take this feature into account. As we will see later on, the presence of this feature has important consequences for the optimal design of bank regulation.
} 
return potential, captured by the indirect utility $v$, by making an early withdrawal of their $\$ 1$ investment. In contrast, if banks lend out some or all of the amount deposited, depositors with $P$-type accounts facing liquidity needs can withdraw only the fraction $\theta_{j}<1$ and, therefore, gain a utility of $\theta_{j} v$ from an early withdrawal. The Hotelling model represents a convenient analytical device to evaluate the consequences of intensified competition. More intense competition is captured by lower values of the parameter $\tau$. With $\tau$ close to zero the model approaches an industry with perfect competition.

Finally, observe that (1) implies that interest on $P$-type accounts is paid to depositors on the entire amount of their $\$ 1$ deposit regardless of whether and how much they withdraw in period 1 upon realizing a liquidity need. One interpretation for this formulation is that banks pay interest only between periods 1 and 2 but not between periods 2 and 3 . This is clearly a simplification of our model, which is necessary for obtaining closed-form solutions in all stages of the model. ${ }^{4}$

\subsection{Banks}

Banks $A$ and $B$ set their interest rates, $i_{A}$ and $i_{B}$, to be paid on the interest-bearing $P$-type accounts, and the fees, $f_{A}$ and $f_{B}$, levied on $L$-type accounts, subject to the regulator's imposition of the fraction of $P$-type accounts, $\delta$, and the minimum reserve requirement, $\rho$, applied to $P$-type accounts. Let $r$ denote a bank's return on an outside investment project. Let $q_{j}^{P}(\lambda)$ and $q_{j}^{L}(\lambda)$ denote the number of partially liquid and liquid accounts opened with bank $j$ by depositors of type $\lambda$. Then, each bank $j, j=A, B$, chooses interest paid on $P$-type accounts and fee levied on $L$-type accounts to solve

$$
\max _{i_{j}, f_{j}} \pi_{j}=\int_{\left\{\lambda \mid q_{j}^{P}(\lambda)>0\right\}}\left[(1-\rho) r-i_{j}\right] q_{j}^{P}(\lambda) d \lambda+\int_{\left\{\lambda \mid q_{j}^{L}(\lambda)>0\right\}} f_{j} q_{j}^{L}(\lambda) d \lambda .
$$

The first term measures the profit bank $j$ earns from partially-liquid accounts. On each $P$-type account, the bank's return is determined by the difference $(1-\rho) r-i_{j}$, which reflects that the fraction $\rho$ of the deposits into $P$-type accounts has to be held as liquid reserves. The second term in (2) measures the revenue collected from the fees on liquid accounts.

\subsection{Summary of the model}

Table 1 displays the two types of bank accounts in which consumers can choose to deposit their money.

\footnotetext{
${ }^{4}$ A "more realistic" formulation of (1) would be to assume that depositors in $P$-type accounts with bank $A$ gain an expected utility of $\beta-\tau x+\lambda \theta_{A} v+(1-\lambda) i_{A}+\lambda\left(1-\theta_{A}\right) i_{A}$. Under this formulation, holders of $P$-type accounts with bank $A$ receive interest payments in the events that they don't realize a liquidity need, with probability $(1-\lambda)$, and also on the fraction $\left(1-\theta_{A}\right)$ of the amount that they are not able to withdraw in an event of a liquidity need, with probability $\lambda$.
} 
Table 1 A summary of partially-liquid and liquid bank accounts.

\begin{tabular}{lccc}
\hline & $P$-type account & $L$-type account & Decision maker \\
\hline Fee & None & $f_{A}, f_{B}$ & Banks \\
Interest & $i_{A}, i_{B}$ & none & Banks \\
Available funds & $\theta_{A}, \theta_{B}$ & $100 \%$ & Endogenous \\
Fraction of accounts & $\delta$ & $1-\delta$ & Regulator \\
Reserve requirement & $\rho$ & $100 \%$ & Regulator \\
\hline
\end{tabular}

\section{Equilibrium interest rates and fees}

Figure 1 describes an arbitrary allocation of depositors between the banks and it illustrates depositors' choices of whether to open a partially-liquid account or a liquid account. As we demonstrate below, Figure 1 delineates an out-of-equilibrium allocation in the sense that banks do not necessarily apply identical interest rates and fees. ${ }^{5}$

In view of Figure 1 and the utility function (1), depositors who choose to open a $P$-type account and are indifferent between banks $A$ and $B$ are indexed by

$$
x^{P}=\frac{1}{2}+\frac{\lambda v\left(\theta_{A}-\theta_{B}\right)+i_{A}-i_{B}}{2 \tau} .
$$

In Figure 1, $x^{P}$ is drawn as a function of the depositors' probability of facing liquidity shocks for an out-of-equilibrium case where $i_{A}>i_{B}$ and $\theta_{A}<\theta_{B}$, just for the sake of illustration. Clearly, depositors indexed close to $\lambda=0$ have a very low probability of realizing liquidity needs and, therefore, compare mainly the interest rates, $i_{A}$ and $i_{B}$, paid by the banks. In the limit, when $\lambda=0$, more depositors will choose bank $A$ over $B$ if and only if $i_{A}>i_{B}$.

However, as $\lambda$ increases towards $\delta$, depositors also compare the available funds for withdrawal upon realizing liquidity needs as given by $\theta_{A}$ and $\theta_{B}$. Figure 1 assumes that $\theta_{A}<\theta_{B}$ so depositors with high probability of realizing a liquidity need find bank $A$ less attractive; hence, $x^{P}$ is declining with $\lambda$.

The utility function (1) implies that depositors who choose to open a liquid account and are indifferent between banks $A$ and $B$ are indexed by

$$
x^{L}=\frac{1}{2}+\frac{f_{B}-f_{A}}{2 \tau} .
$$

In Figure $1, x^{L}$ is drawn as a constant that is affected only by the difference in fees, $f_{B}-f_{A}$. $x^{L}$ is independent of $\lambda$ because depositors can always withdraw the full amounts; that is, $\theta_{A}=\theta_{B}=1$ on liquid accounts.

\footnotetext{
${ }^{5}$ For the sake of illustration, only Figure 1 displays an out-of-equilibrium allocation of depositors among the banks. This might result in deviations from the mandated ratios of $\rho$ and $\delta$. Because in practice the regulating authority can observe only equilibrium values, we only need to verify that in equilibrium each bank separately observes the mandated ratios $\rho$ and $\delta$, whereas out of equilibrium this need not always be the case.
} 


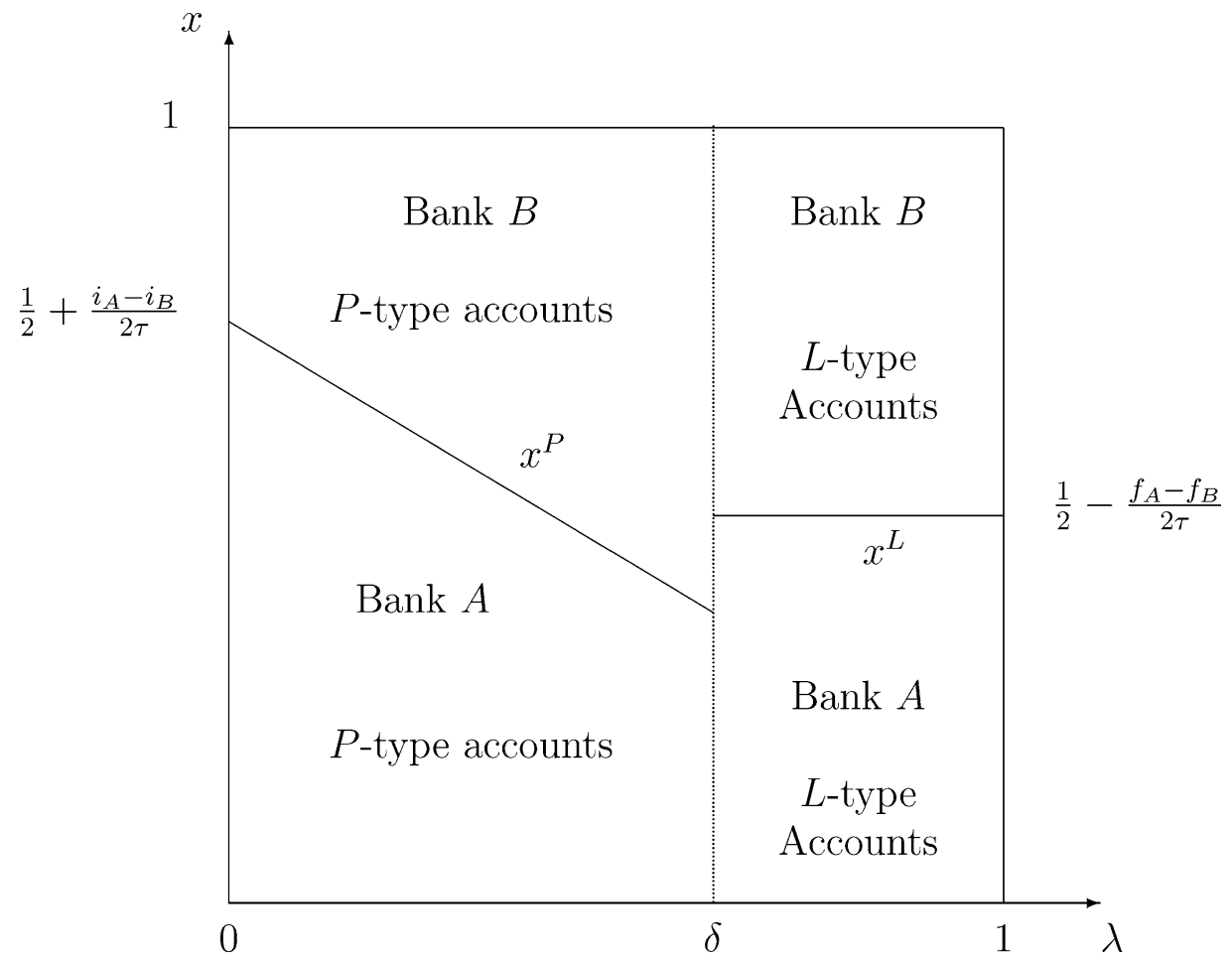

Figure 1 Possible (out-of-equilibrium) allocation of depositors among banks and account types.

\subsection{Banks' optimization}

In view of Figure 1 , for each $\lambda$ with $0 \leq \lambda \leq \delta$, the number of type $\lambda$ depositors opening $P$-type accounts with each bank are $q_{A}^{P}(\lambda)=x^{P}(\lambda)$ and $q_{B}^{P}(\lambda)=1-x^{P}(\lambda)$. The total number of liquid accounts are $q_{A}^{L}=(1-\delta) q_{A}^{L}(\lambda)=(1-\delta) x^{L}$ and $q_{B}^{L}=(1-\delta) q_{B}^{L}(\lambda)=(1-\delta)$ $\left(1-x^{L}\right)$, as these liquid accounts are chosen by all $\lambda$ types with $\delta \leq \lambda \leq 1$. In the above, $x^{P}$ and $x^{L}$ are given in (3) and (4), respectively.

Now, in view of Figure 1, the imposed regulation that a fraction $\delta$ of all accounts has to be maintained as partially liquid, implies that depositors indexed by $\lambda=\delta$ must be indifferent between opening a $P$-type account and an $L$-type account. Therefore, substituting $\lambda=\delta$ into the utility function (1), we have $\beta-\tau x+i_{A}+v \theta_{A} \delta=\beta-\tau x-f_{A}+v \delta$ for bank $A$, and analogously for bank $B$. Hence, the fee levied on liquid accounts in bank $j$ can be expressed as

$$
f_{j}=\delta v\left(1-\theta_{j}\right)-i_{j}, \quad j=A, B .
$$

Substituting (5) into (4), we obtain

$$
x^{L}=\frac{1}{2}+\frac{\delta v\left(\theta_{A}-\theta_{B}\right)+i_{A}-i_{B}}{2 \tau} .
$$


Substituting (3), (5), and (6) into (2), the optimization problem facing each bank $j$ is reduced to the problem of choosing the interest rate paid on $P$-type accounts according to

$$
\begin{aligned}
\max _{i_{j}} \pi_{j}= & \int_{0}^{\delta}\left[(1-\rho) r-i_{j}\right]\left[\frac{1}{2}+\frac{\lambda v\left(\theta_{j}-\theta_{k}\right)+i_{j}-i_{k}}{2 \tau}\right] d \lambda \\
& +\left[\delta v\left(1-\theta_{j}\right)-i_{j}\right](1-\delta)\left[\frac{1}{2}+\frac{\delta v\left(\theta_{j}-\theta_{k}\right)+i_{j}-i_{k}}{2 \tau}\right],
\end{aligned}
$$

where $j, k=A, B$ and $j \neq k$.

It should be emphasized that banks treat the fraction of available funds that can be withdrawn from $P$-type accounts, $\theta_{A}$ and $\theta_{B}$, as variables and not as constants. Therefore, the following section computes the endogenously-determined values of $\theta_{A}$ and $\theta_{B}$ to be substituted into the profit functions (7) before maximizing profits with respect to the deposit rates $i_{A}$ and $i_{B}$.

\subsection{Equilibrium liquid funds under rational expectations}

To calculate the equilibrium interest rates, $i_{A}$ and $i_{B}$, we must first compute $\theta_{A}$ and $\theta_{B}$ as functions of the interests rates to be substituted into the profit functions (7). Denote by $w_{j}^{P}$ the expected number of those depositors with bank $j$ 's $P$-type accounts who realize a liquidity need in period 2. Formally,

$$
\begin{aligned}
& w_{A}^{P}=\int_{0}^{\delta} \lambda x^{P} d \lambda=\frac{\delta^{2}\left[3\left(i_{A}-i_{B}\right)+2 v \delta\left(\theta_{A}-\theta_{B}\right)+3 \tau\right]}{12 \tau} \\
& w_{B}^{P}=\int_{0}^{\delta} \lambda\left(1-x^{P}\right) d \lambda=\frac{\delta^{2}\left[3\left(i_{B}-i_{A}\right)+2 v \delta\left(\theta_{B}-\theta_{A}\right)+3 \tau\right]}{12 \tau} .
\end{aligned}
$$

The number of $P$-type accounts, $q_{A}^{P}$ and $q_{B}^{P}$, is equal to the total dollar amounts deposited in these $P$-type accounts. However, with a required reserve ratio of $\rho$, the banks maintain only $\rho q_{A}^{P}$ and $\rho q_{B}^{P}$ in the form of liquid cash from $P$-type accounts. Therefore, the expected amounts of money that can be withdrawn by each depositor who deposits $\$ 1$ in bank $A$ 's $P$-type account (similarly bank $B$ ) are

$$
\theta_{A}=\frac{\rho q_{A}^{P}}{w_{A}^{P}}=\frac{3 \rho\left[2\left(i_{A}-i_{B}\right)+v \delta\left(\theta_{A}-\theta_{B}\right)+2 \tau\right]}{\delta\left[3\left(i_{A}-i_{B}\right)+2 v \delta\left(\theta_{A}-\theta_{B}\right)+3 \tau\right]},
$$

and

$$
\theta_{B}=\frac{\rho q_{B}^{P}}{w_{B}^{P}}=\frac{3 \rho\left[2\left(i_{B}-i_{A}\right)+v \delta\left(\theta_{B}-\theta_{A}\right)+2 \tau\right]}{\delta\left[3\left(i_{B}-i_{A}\right)+2 v \delta\left(\theta_{B}-\theta_{A}\right)+3 \tau\right]} .
$$

The fractions of funds available for withdrawal by depositors who realize liquidity needs, $\theta_{A}$ and $\theta_{B}$, are determined by solving the system equations (10) and (11), which may 
yield three solutions. However, as it turns out, for any (equilibrium or out-of-equilibrium) interest-rate levels $i_{A}$ and $i_{B}$, a symmetric solution always exists and is given by

$$
\theta_{A}=\theta_{B}=\left\{\begin{array}{ll}
\frac{2 \rho}{\delta} & \text { for } \rho \leq \frac{\delta}{2} \\
1 & \text { for } \rho>\frac{\delta}{2}
\end{array} .\right.
$$

Equation (12) and the utility function (1) imply that there is no benefit from establishing a reserve requirement $\rho>\delta / 2$. This means that the regulator's choice of a socially optimal reserve ratio, analyzed in Section 4 , can be restricted to the interval $[0, \delta / 2]$, instead of $[0,1]$. In particular, the requirement $\rho \leq \delta / 2$ means that there is no gain from imposing a reserve requirement in a world with narrow banking (with $\delta=0$ ), because under narrow banking all accounts are 100 percent liquid.

\subsection{Equilibrium interest rates and fees}

Substituting (12) into the profit functions (7), then maximizing $\pi_{A}$ with respect to $i_{A}$ and $\pi_{B}$ with respect to $i_{B}$, we find the equilibrium interest rates paid on accounts with partial liquidity to be

$$
i_{A}=i_{B}=r \delta(1-\rho)+v(1-\delta)(\delta-2 \rho)-\tau .
$$

Next, substituting (13) into (5) yields the banks' fee levied on each liquid account

$$
f_{A}=f_{B}=v\left(\delta^{2}-2 \delta \rho\right)+\tau-r \delta(1-\rho) .
$$

Note that at this stage we are not concerned with whether the equilibrium interest rates are strictly positive, as in principle there is no reason for ruling out negative interest rates, which could be interpreted as fees on $P$-type accounts. Under this interpretation, negative fees imposed on $L$-type accounts imply that $L$-type accounts also pay some interest. We will explore some exact equilibrium values of interest rates and fees in Section 4, which computes the exact values of the socially-optimal regulatory variables, $\delta$ and $\rho$.

The following proposition demonstrates how the equilibrium interest rates and fees given in (13) and (14) are affected by the regulatory instruments and the parameters of the model.

Proposition 1 In a duopoly banking industry where banks compete on interest rates paid on partially-liquid accounts, and fees levied on liquid accounts, for every bank $j=A, B$ :

(i) An increase in the degree of competition (a reduction in $\tau$ ) increases equilibrium interest rates, and reduces equilibrium fees. Formally, $d i_{j} / d \tau=-1<0$ and $d f_{j} / d \tau=1>0$.

(ii) An increase in the mandated reserve requirement of $P$-type accounts reduces the equilibrium interest rates paid on P-type accounts. Formally, $d i_{j} / d \rho<0$. In this case, equilibrium fees decline; that is, $d f_{\mathrm{j}} / d \rho<0$ if and only if the return on the private investment opportunity satisfies $v>r / 2$. 
(iii) An increase in the return on banks' investment $r$, increases equilibrium interest paid on $P$-type accounts, and reduces the fees levied on L-type accounts. Formally, $d i_{j} / d r>0$ and $d f_{\mathrm{j}} / d r<0$.

Proposition 1(i) is rather intuitive, because a decrease in a degree of bank differentiation in depositor preferences (a decrease in $\tau$ ) induces banks to raise interest paid on $P$-type deposits and to reduce the fees on $L$-type deposits. Part (ii) demonstrates that those who deposit into $P$-type accounts are willing to trade higher reserves for lower interest. In this respect, higher reserves operate in a way that is equivalent to relaxed competition between the banks. Fees might decline because $P$ accounts become more attractive to depositors for sufficiently high return on private investment, $v$. Part (iii) captures the idea that banks transfer some gains from an increase in their investment return $r$ to depositors in the form of higher interest on deposits and lower fees on liquid accounts.

\section{Regulation and social welfare}

In this section we approach the climax of our analysis. We characterize the socially optimal combination of the two regulatory instruments: (i) the reserve requirement on partiallyliquid accounts, $\rho^{*}$; and (ii) the mandated maximum fraction of partially-liquid accounts, $\delta^{*}$. In particular, we characterize the conditions under which it is socially optimal to require that banks maintain a certain fraction of accounts 100 percent liquid, meaning that $\delta^{*}<1$.

To find the aggregate banking industry profit, substituting (12), (13) and (14) into (7) yields

$$
\Pi=\pi_{A}+\pi_{B}=\frac{\tau}{2}+\frac{\tau}{2}=\tau
$$

Next, we define aggregate depositor surplus as the sum of depositors' equilibrium utility levels. From (1) we have

$$
D S \stackrel{\text { def }}{=} 2 \int_{0}^{\delta} \int_{0}^{0.5}\left[\beta-\tau x+v \theta \lambda+i_{A}\right] d x d \lambda+2 \int_{\delta}^{1} \int_{0}^{0.5}\left[\beta-\tau x+v \lambda-f_{A}\right] d x d \lambda,
$$

where $\theta=2 \rho / \delta$ by (12). The first term in (16) is the equilibrium aggregate surplus of bank $A$ depositors in $P$-type accounts (we multiply by " 2 " to add the utility of depositors with bank $B$ ). The second term is the equilibrium aggregate surplus from liquid accounts (where $\theta_{A}=\theta_{B}=1$ because all deposits are available for withdrawal).

We define the social welfare function as the sum of depositors' utilities and aggregate banking industry profit. Substituting (12), (13) and (14) into (16), the regulator chooses $\rho$ and $\delta$ to maximize the social welfare

$$
\max _{\rho, \delta} W=D S+\Pi=\beta+r \delta(1-\rho)+\frac{2 v\left(1-\delta^{2}+2 \delta \rho\right)-\tau}{4} .
$$


Differentiating (17) yields

$$
\frac{\partial W}{\partial \rho}=\delta(v-r) \quad \text { and } \quad \frac{\partial W}{\partial \delta}=(1-\rho) r+(\rho-\delta) v=0 .
$$

Therefore, for a given $\delta$, the reserve requirement maximizing social welfare is

$$
\rho^{*}= \begin{cases}\frac{\delta}{2} & \text { if } v>r \\ 0 & \text { if } v<r\end{cases}
$$

where the value for the maximal $\rho$ is taken from (12). Substituting (19) into (18) yields

$$
\delta^{*}=\left\{\begin{array}{ll}
\frac{2 r}{r+v} & \text { if } v>r \\
\min \left\{\frac{r}{v}, 1\right\}=1 & \text { if } v<r
\end{array} \text { hence } \rho^{*}= \begin{cases}\frac{r}{r+v} & \text { if } v>r \\
0 & \text { if } v<r .\end{cases}\right.
$$

Observe that $v>r>0$ also ensures that $0<\delta^{*}<1$ and $0<\rho^{*}<1$.

Now, we are ready to state our main proposition

Proposition 2 (a) If the return on depositors' early withdrawal exceeds banks' investment return, formally if $v>r$, then the socially-optimal reserve requirement and the fraction of partially-liquid accounts are given by

$$
\rho^{*}=\frac{r}{r+v} \text { and } \quad \delta^{*}=\frac{2 r}{r+v} .
$$

(b) In contrast, if $v<r$ then $\rho^{*}=0$ and $\delta^{*}=1$.

Proposition 2(b) can be seen as characterizing the circumstances under which the commonly observed banking system with partial liquidity is socially optimal. In light of Proposition 2(b), the current system with very low reserve requirements seems justified if it holds true that the returns of the investment projects funded by banks exceed those of depositors realizing a liquidity need. This could be the case if the banks offer value-adding inputs (e.g. valuable expertise) to the funded projects, and if the credit market frictions are low.

The particular novelty of the present paper is the characterization of the opposite case given in Proposition 2(a), which holds for $v>r$. Namely, if the returns of the investment projects funded by banks fall short of depositors' opportunity associated with the realizations of the liquidity needs, the socially optimal policy is for the regulator to require that banks maintain some 100 percent liquid accounts in addition to the imposition of a reserve requirement on partially-liquid accounts. This seems to be a natural case, because the returns on banks' portfolios are ultimately derived from the returns on projects pursued by individuals.

The authors of the present paper are not aware of any commercial bank that offers depositors 100 percent-liquid accounts; that is, all dollars are kept at the bank's safe or deposited with the central bank. Proposition 2(a) states the condition under which the currently-observed banking system where banks do not offer any perfectly-liquid accounts to depositors is inefficient. Under this condition, social welfare is maximized when 
commercial banks segment depositors according to their privately known probability of realizing liquidity needs. Under this regulation, as Figure 1 illustrates, depositors with high probabilities $\left(\lambda>\delta^{*}\right)$ of realizing liquidity needs will choose to have their banks maintain 100 percent reserves on their funds. In addition, depositors with low probabilities of realizing liquidity needs $\left(\lambda \leq \delta^{*}\right)$ will choose to open accounts with partial liquidity subjected to a $\rho^{*}$ reserve requirement.

For the case where $v>r$ we are able to compute the exact welfare gains associated with the adoption of mixed banking regulation given by (20) and to compare it to the commonly-observed banking policy with partially liquid accounts. See Definition 1 for the classification of regulatory regimes. By substituting the optimal policy instruments (20) into the welfare function (17), we find that the mixed banking regime will achieve the following level of social welfare for $v>r$ :

$$
W^{M B}=\beta+\frac{10 v-\tau}{4}-\frac{2 v^{2}(2 r+v)}{(r+v)^{2}} .
$$

Suppose now instead that the regulator mandates a banking system with partially liquid accounts. Setting $\delta^{*}=1$ (all accounts are partially-liquid) implies that the reserve requirement should be set to $\rho^{*}=\delta^{*} / 2=1 / 2$. Substituting the two policy instruments into (17) yields the social welfare level

$$
W^{P L}=\beta+\frac{2(r+v)-\tau}{4} .
$$

Now, for the case where $v>r$, the welfare gain from implementing mixed banking over the partially-liquid banking is computed by

$$
\Delta W=W^{M B}-W^{P L}=2 v-\frac{r}{2}-\frac{2 v^{2}(2 r+v)}{(r+v)^{2}}>0 .
$$

It should be emphasized that the optimal policy characterized by Proposition 2 is independent of the banking market imperfection as captured by the parameter $\tau$. In other words, the optimal policy combination is invariant to the intensity of competition. One explanation for this is that the equilibrium proportion of illiquid accounts is not affected by the degree of competition. Competition indeed affects fees and interest rates, as Proposition 1(a) shows, but in equilibrium the proportion of illiquid accounts is related only to the probability and associated benefit of realizing a liquidity need.

Clearly, the mechanism analyzed in this paper can be extended to cover banking industries offering a spectrum of deposit contracts with different degrees of liquidity. No matter how complete this spectrum is, the basic mechanism highlighted in this paper holds true. Namely, the introduction of perfectly liquid accounts will improve welfare as the implied liquidity segmentation makes it possible to sustain price discrimination, whereby the costs of liquidity-providing regulation are carried only by the depositors with a sufficiently high probability of facing a liquidity need.

Finally, note that depositors' utility functions defined by (1) reflect risk neutrality. Clearly, assuming risk aversion would make our argument concerning the benefits from mixed banking relative to partially-liquid banking even stronger. However, it turns out that 
assuming risk neutrality not only makes this model explicitly solvable, but also sheds some light on the role of a regulator implementing mixed banking. To be more precise, we now compute the equilibrium interest rates, fees and the fraction of cash in $P$-type accounts available for withdrawal when the socially-optimal policy (20) is implemented. Substituting (20) and (12) into (13) and (14) yields

$$
i_{j}^{*}=-f_{j}^{*}=2 v-\tau-\frac{2 v^{2}(2 r+v)}{(r+v)^{2}} \quad \text { and } \quad \theta_{j}=1, \quad \text { for banks } j=A, B .
$$

Therefore, for risk neutral depositors (analyzed in this paper), the regulator sets up the two regulatory instruments so that the expected benefit from $P$-type accounts and $L$-type accounts are equalized. This means that on average, $P$-type accounts should be able to meet the liquidity needs ( $a s \theta_{j}=1$ ) and, hence, both types of accounts will bear the same interest rates (or fees, if negatives). From this, we can conclude that under risk aversion, interest paid on $L$-type accounts will be lower than interest paid on $P$-type accounts because $L$-type accounts provide complete insurance.

\section{Conclusion}

Our paper points out the social inefficiency implied by the feature that the present regulatory design of the banking system rules out perfectly liquid and safe banking as a financial product. In the absence of this financial product banks have an incentive to bundle the deposit activities with their risk taking.

In this article we have extended the set of instruments for regulating banks' liquidity provision by adding the fraction of perfectly-liquid accounts as an additional regulatory instrument. We have demonstrated how the presence of this added instrument will induce self-selection on behalf of the depositors, who are differentiated according to their probability of facing a liquidity shock. This self-selection will lead to a market segmentation, which can break the bundling of deposits with liquidity risk and, thereby, enhance welfare. In this respect, our analysis characterized those circumstances under which the addition of perfectly-liquid deposit accounts could represent a Pareto improvement relative to a banking industry where risky accounts represent the only channel whereby consumers can enjoy the financial services offered by the banks.

We derived the socially optimal regulatory policy when the set of policy instruments includes the fraction of perfectly-liquid accounts in addition to the traditional reserve requirements applied on risky accounts. The optimal policy was explicitly characterized as a function of banks' investment return and the return of depositors realizing a liquidity shock. In particular, we outlined the conditions under which the currently applied policy of applying only reserve requirements or under which a system with extreme narrow banking would be optimal.

Our analysis has ignored the widely observed system of deposit insurance for the simple reason that the benchmark for optimal regulation should always be characterized without any additional distortions of banks' incentives for maintaining liquidity to meet the potential needs of depositors. Once deposit insurance is introduced, banks have no 
incentives to compete with respect to liquidity provision, because liquidity is then guaranteed within the framework of this insurance system. The present model, with fairly minor and straightforward modifications, can be extended so as to enable a comparison of deposit insurance systems with systems incorporating a mandated fraction of perfectly liquid deposit accounts.

\section{References}

Bryant, J. (1980), “A model of reserves, bank runs, and deposit insurance,” Journal of Banking and Finance 4, 335-44.

Cooper, R., and T. Ross (1998), "Bank runs: Liquidity costs and investment distortions," Journal of Monetary Economics 41, 27-38.

Diamond, D., and P. Dybvig (1983), "Bank runs, deposit insurance, and liquidity," Journal of Political Economy 91, 401-19.

Diamond, D., and R. Rajan (2001), "Liquidity risk, liquidity creation and financial fragility: A theory of banking," Journal of Political Economy 109, 287-327.

Feldman, R., and A. Rolnick (1998), "Fixing FDICIA: A plan to address the too-big-to-fail problem," Federal Bank of Minneapolis, 1997 Annual Report Essay.

Freixas, X., and J.-C. Rochet (1997), Microeconomics of Banking, Cambridge, MA: The MIT Press.

Friedman, M. (1960), A Program for Monetary Stability, New York: Fordham University Press.

Kashyap, A., R. Rajan, and J. Stein (2002), "Banks as liquidity providers: An explanation for the co-existence of lending and deposit-taking," Journal of Finance 57, 33-73.

Kay, J. (1998), “The key to the banks,” Financial Times, 14 October.

Wallace, N. (1996), "Narrow banking meets the Diamond-Dybvig model,” Federal Bank of Minneapolis Quarterly Review 20, 3-13.

Villamil, A. (1991), "Demand deposit contracts, suspension of convertibility, and optimal financial intermediation," Economic Theory 1, 277-88. 